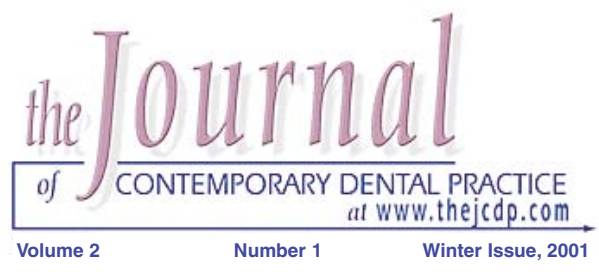

\title{
Evaluation of a Digital Measurement Tool to Estimate Working Length in Endodontics
}

\author{
Federico Lamus, DDS; Jerald O. Katz, DMD, MS; Alan G. Glaros, PhD
}

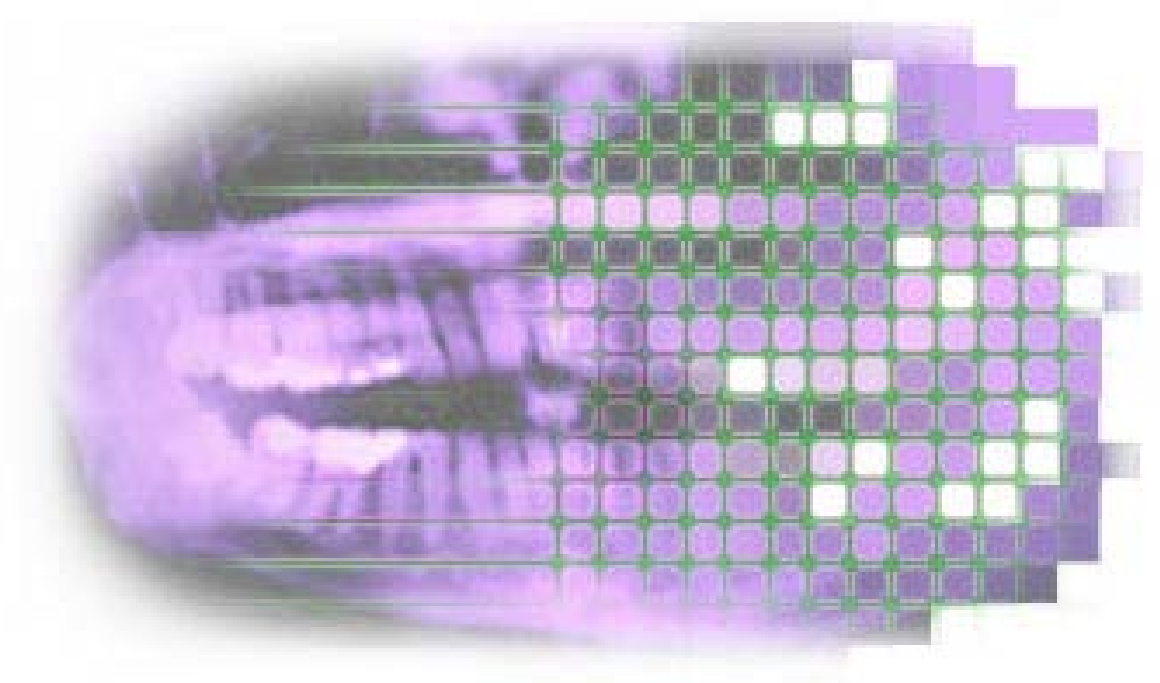

The purpose of the study was to compare the segmental measurement tool from the Shick Technologies CDR digital system with the conventional film radiography measurement technique to determine preoperative working length. Natural extracted human teeth with varying degrees of root curvature were used. All teeth were imaged using the Shick Technologies CDR direct digital system and conventional E-speed film. Measurements from digital radiography and conventional film were compared with measurements made directly from the endodontic files. The Wilks' Lambda multivariate test was used. The mean measurement of each modality was compared with the other and with the gold standard. The test showed statistically significant differences between the two modalities at $p<0.05$. The mean measurements for both modalities were not significantly dif ferent from the gold standard. The modality most closely approaching the gold standard was the conventional film.

Keywords: Direct digital radiography, Schick Technologies CDR, conventional film, working length, endodontics

(c) Seer Publishing 


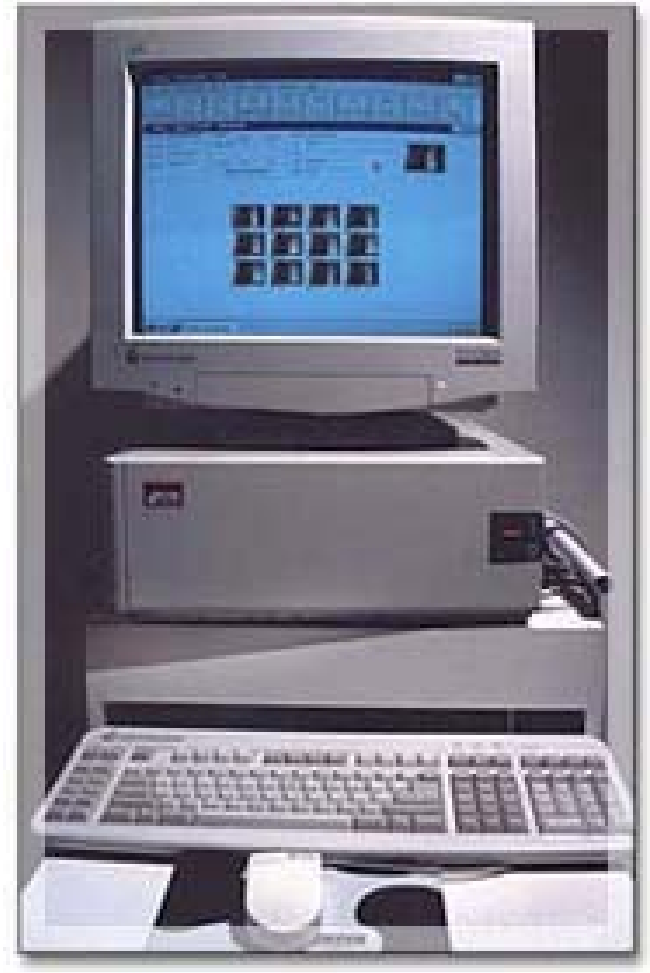

Figure 1

Introduction

Radiology is an essential part of endodontics to ensure successful root canal therapy. It is helpful in estimating and confirming the lengths of root canals and to verify the apical extension of an endodontic file prior to and during instrumentation. Traditionally, the root length is determined initially by measurement of periapical radiographs. ${ }^{1,3}$ However, measurement of roots that are excessively curved is difficult when using this method. With direct digital radiography, segmental measurements may be combined to give the overall working length of a curved root. The accuracy of this segmental measurement tool compared to conventional film measurement techniques has not been tested. Therefore, the aim of this study is to compare the segmental measurement tool from the Shick Technologies CDR digital system with the conventional film radiography measurement technique to determine preoperative working length. (Figure 1)

\section{Materials and Methods}

Twenty extracted human posterior teeth stored at $4^{\circ} \mathrm{C}$ in $0.9 \% \mathrm{NaCl}$ containing $0.002 \%$ sodium azide were used for this pilot study. Teeth with varying degrees of root curvature were selected. An optical bench was used to reproducibly position the X-ray source, teeth, and image receptor.

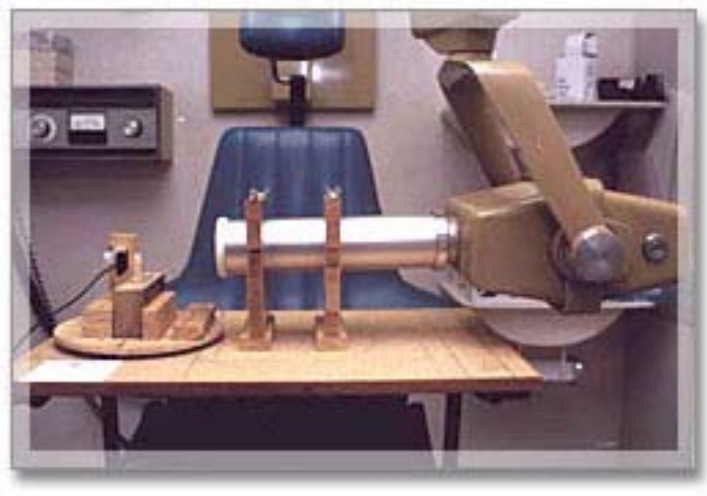

Figure 2

(Figure 2) The standard geometric configuration was fixed at $40-\mathrm{cm}$ source-to-object distance, 1$\mathrm{cm}$ object-to-receptor distance, and zero degrees vertical and horizontal angulation of the $\mathrm{X}$-ray beam.

All teeth were imaged using the Shick Technologies CDR direct digital system and conventional E-speed film. A GE-1000 intraoral X-ray machine was used operated at $70 \mathrm{kVp}$ and $10 \mathrm{~mA}$. The timer settings that were required to produce comparable densities for both conventional film and digital images were determined by consensus of two oral and maxillofacial radiologists. Timer settings were 5 impulses for the CDR images and 14 impulses for conventional film. All intraoral films were processed at the same time in a Hope $\mathrm{P}-10$ automatic processor for 4.5 $\min$. at $82^{\circ} \mathrm{F}$.

After the images were obtained, three experienced endodontists measured the working lengths of twenty root canals from digital images using the segmental measurement tool. (Figure 3) The working lengths from the conventional film were measured using an electronic digital caliper

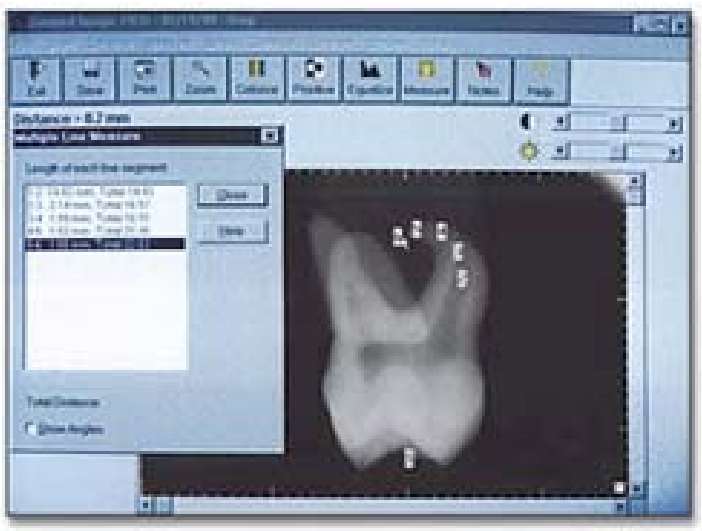

Figure 3 
(Fred Fowler Co., Newton, MA). To determine the actual working lengths, access preparations were made and a K-type size 15 endodontic file was placed in the canals until the file was flush with the apical foramen. Measurements from digital and conventional film were then compared with measurements made directly from the endodontic files.

The Wilks' Lambda multivariate test was used. The mean measurement of each modality was compared with the other and with the gold standard.

\section{Results}

The Wilks' Lambda multivariate test showed statistically significant differences between the two modalities at $p<0.05$. The mean measurements for both modalities were not significantly different from the gold standard. The modality most closely approaching the gold standard was the conventional film. The majority of measurements made from conventional film were shorter than the actual measurement (-.314), while the majority of the measurements made using the digital segmental measurement tool were longer than the actual measurement (.467). (Table 1)

\section{Discussion}

No significant differences between the two modalities and the gold standard were found.

Measurements made from both conventional film and direct digital images were less than $1 \mathrm{~mm}$ different from direct measurements from the extracted teeth. This finding suggests the Shick Technologies CDR digital system may be suitable for use in estimating the preoperative working length in endodontic treatment. Use of this digital system offers the benefits of reduced patient exposure to ionizing radiation and rapid image production without the use of a darkroom. In addition, the digital images may be enhanced to highlight areas of interest.

Difference in measurements from the two modalities were statistically significant, however, the difference was not considered clinically significant at less than $1 \mathrm{~mm}$. Although the difference was small, one of the modalities (direct digital) overestimated, while the other (E-speed film) underestimated working length. One possible explanation may have been the lack of a reference point on the occlusal surface of the teeth from which to make the measurements.

This study found the measurements made using the segmental measurement tool from the Shick Technologies CDR digital system were comparable to those made using conventional film radiography. Additional studies are warranted to further evaluate the direct digital segmental measurement tool.

Table 1. Comparison of direct measurements with measurements made using DDR and conventional film.

\begin{tabular}{|l|l|l|}
\hline & Mean Working Lengths & $\begin{array}{l}\text { Differences from Direct } \\
\text { Measurement }\end{array}$ \\
\hline Direct Measurement & $19.14 \mathrm{~mm}$ & $\mathrm{~N} / \mathrm{A}$ \\
\hline E-speed Film & $18.83 \mathrm{~mm}$ & $-0.31 \mathrm{~mm}$ \\
\hline Digital & $19.61 \mathrm{~mm}$ & $+0.46 \mathrm{~mm}$ \\
\hline
\end{tabular}


1. Ingle Jl. Endodontic instruments and instrumentation. Dent. Clin. North Am., pp. 805-22, November, 1957.

2. Bramante MC. A critical evaluation of some methods of determining tooth length. Oral Surg Oral Med Oral Pathol., pp463-73, March, 1974.

3. Stein TJ, Corcoran JF. Radiographic "working length" revisited. Oral Sur Oral Med Oral Pathol 1992;74: 796-800. 


\section{Federico Lamus, DDS.}

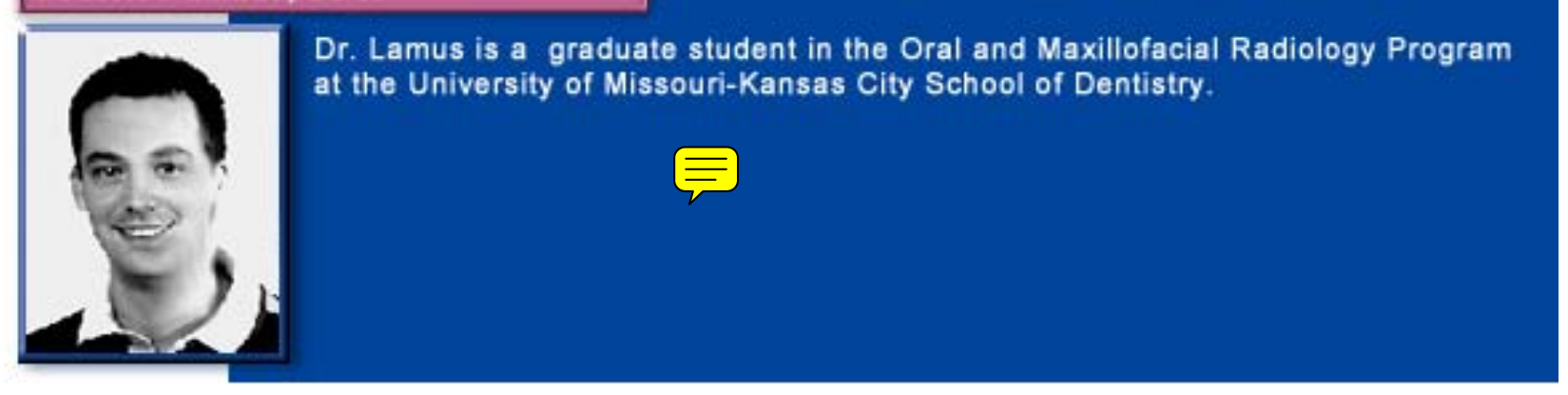

\section{Alan G. Glaros, PhD}

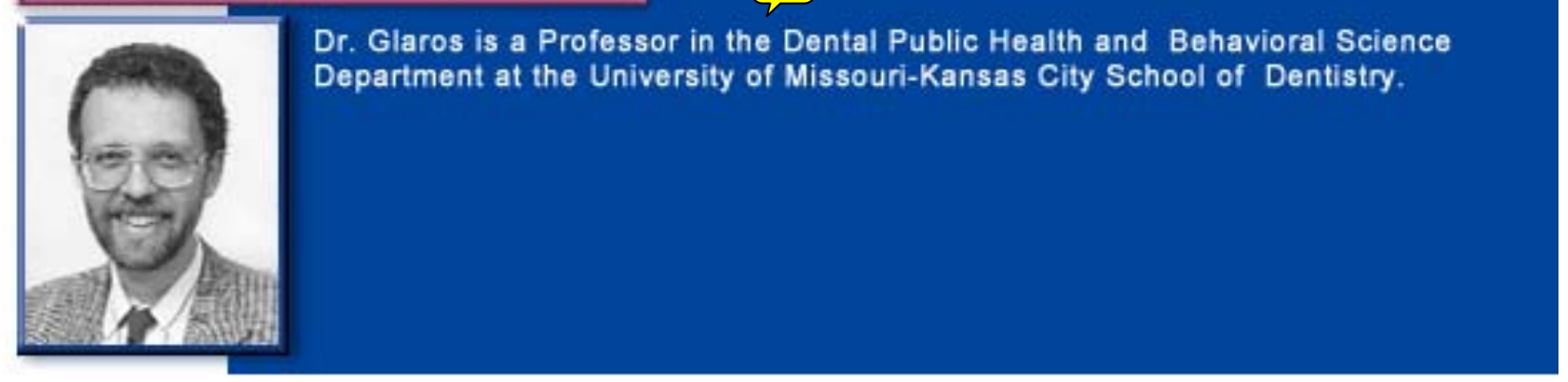

\section{Jerald O. Katz, DMD, MS.}
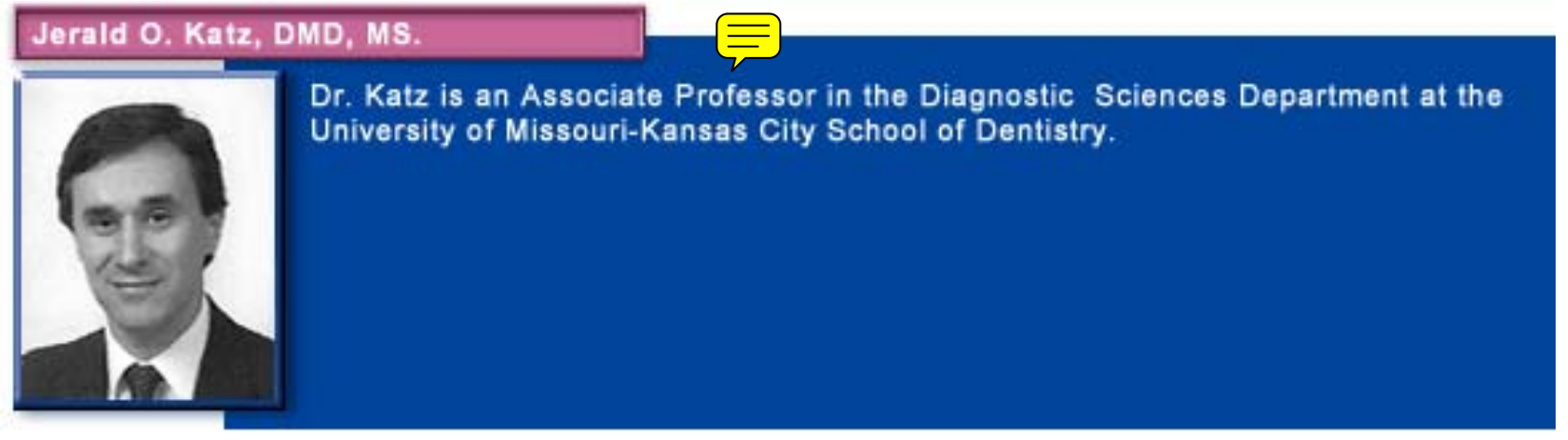